\title{
Urdimento
}

Revista de Estudos em Artes Cênicas E-ISSN: 2358.6958

\section{Theru-K-Koothu e o mundo desencantado: Caminhos e descaminhos de uma tradição ritual}

Irani Cippiciani

\section{Para citar este artigo:}

CIPPICIANI, Irani. Theru-K- Koothu e o mundo desencantado: Caminhos e descaminhos de uma tradição ritual. Urdimento, Florianópolis, v. 1, n. 40, mar./abr. 2021.

do) DOI: http:/dx.doi.org/10.5965/1414573101402021e0108

Este artigo passou pelo Plagiarism Detection Software | iThenticate 
Theru-K- Koothu e o mundo desencantado:

Caminhos e descaminhos de uma tradição ritual

Irani Cippiciani ${ }^{1}$

\begin{abstract}
Resumo
Este artigo trata dos dilemas enfrentados pelos artistas de Theru-K-Koothu, forma teatral folclórica do estado de Tamil Nadu, Índia, quando deslocados de seu contexto ritual, comunitário e agrário, e lançados em um mundo globalizado e urbano, onde o imaginário coletivo e a organização social diferem daquela em que esta manifestação cultural foi gestada. Desse modo, analisa as consequências e desdobramentos deste choque entre sistemas de valores tão diferentes sobre os artistas, suas redes de relações e sobre a própria estrutura da encenação, tomando emprestado o conceito de "desencantamento do mundo" de Weber, avançando para a dimensão que ele toma nos escritos de Fischer-Lichte, em cruzamento com o conceito de "liminaridade" apresentado por Caballero. A pergunta que se levanta desse encontro é: o que o Theru-K-Koothu pode nos dizer sobre nosso próprio desencanto e quais estratégias pode nos oferecer como antídoto a ele?
\end{abstract}

Palavras-chave: Theru-K-Koothu. Teatro Folclórico. Índia. Estudos da Performance.

Theru-K-Koothu and the disenchanted world:

Paths and mispaths of a ritual tradition

\begin{abstract}
This article addresses the dilemmas faced by the artists of Theru-K-Koothu, folkloric theatrical form of the state of Tamil Nadu, India, when displaced from their ritual, community and agrarian context, and launched into a globalized and urban world, where the collective imaginary and social organization differ from that where this cultural manifestation was gestated. Thus, analyzes the consequences and ramifications of this clash between two very different value systems on the artists, its networks and on the very structure of the performance, taking as argument the concept of "disenchantment of the world" of Weber, advancing to the dimension that the concept gets in the writings of Fischer-Lichte, in connection with the concept of "liminality" expressed by Caballero. The question that arises from this unusual encounter is: what can Theru-K-Koothu tell us about our own disenchantment and what strategies can it offer us as an antidote to it?
\end{abstract}

Keywords: Theru-K-Koothu. Folk Theatre. India. Performance Studies.

${ }^{1}$ Atriz, dançarina, professora e pesquisadora. Formada em Artes Cênicas pela ECA/USP, desenvolveu suas pesquisas de mestrado e doutorado no IA/UNICAMP, acerca da profícua cultura teatral indiana, clássica e folclórica. iranicippiciani@gmail.com

http://lattes.cnpq.br/3064508473315571

https://orcid.org/0000-0001-8213-3816 
Theru-K-Koothu y el mundo desencanto:

Caminos y desviaciones de una tradición ritual

\section{Resumen}

Este artículo aborda los dilemas que enfrentan los artistas de Theru-K-Koothu, una forma teatral folklórica del estado de Tamil Nadu, India, cuando desplazado de su contexto ritual, comunitario y agrario, y lanzado a un mundo globalizado y urbano, donde la imaginación colectiva y la organización social difiere de aquella donde se creó esta manifestación cultural. De esta manera, analiza las consecuencias y desarrollos de este choque entre sistemas de valores tan diferentes en los artistas, sus redes de relaciones y en la estructura misma puesta en escena, tomando prestado el concepto de Weber de "desencanto del mundo", avanzando a la dimensión que toma en los escritos de Fischer-Lichte, en cruce con el concepto de "liminalidad" presentado por Caballero. La pregunta que surge de esta reunión es: ¿qué puede decirnos Theru-K-Koothu sobre nuestro propio desencanto y qué estrategias nos puede ofrecer como antídoto?

Palavras clave: Theru-K-Koothu. Teatro Folclórico. Índia. Estúdios de Performance. 


\section{Draupadi Amman² e o Theru-K-Koothu}

Figura 1 - Amman, divindade feminina dravidiana. Foto: Edilson Castanheira



O Theru-K-Koothu é o representante mais ilustre de uma vasta gama de estilos teatrais folclóricos de Tamil Nadu, no sul da Índia. Theru quer dizer "espaço a céu aberto" e Koothu "dança, teatro, divertimento ou situação melodramática", segundo o dicionário de Inglês-Tâmil, configurando um estilo de teatro folclórico e ritual, feito em espaços comunitários ou mesmo na rua. Etimologicamente, a palavra Koothu é encontrada na literatura do período clássico Tâmil, conhecido como Cankam, que vai de 100 a.C. a 600 d.C., e descende da raiz Kuvu (calling out, summoning scream), significando "[...] encenações rituais envolvendo possessão sagrada e transe" (Hollander, 2007, p. 159) ${ }^{3}$.

${ }^{2}$ Draupadi é a personagem feminina mais importante do épico Mahabharata, esposa dos cinco irmãos Pandavas, representantes do Dharma na Terra.

${ }^{3}[\ldots]$ ritual enactments involving sacred possession and trance. (Hollander, 2007, p. 159 apud Frasca, 
Sua origem remonta aos rituais dravidianos, anterior ao período védico, com fortes elementos anímicos, fundindo conteúdos históricos, morais, educacionais e religiosos que auxiliam no processo de ordenação social e espiritual das comunidades rurais onde se insere, garantindo sua saúde material e simbólica enquanto indivíduos e coletividade. Há vestígios importantes desta tradição na Dinastia Pallava, entre 275-897 da era cristã, numa linha do tempo, para frente e para trás, de aproximadamente 1.300 anos. Historicamente, acredita-se que o Theru-K-Koothu, como conhecemos hoje, não tenha mais do que três séculos de existência.

O Theru-K-Koothu pode ser entendido como o amálgama do culto às divindades femininas regionais, as Ammans, do culto Vaishnava, manifesto por meio da disseminação do épico Mahabharata (Frasca, 1990, p. 135), no qual Krishna (irmão de Draupadi) é a grande divindade, e da cultura militar que vigorava na região por volta do século XV - época de florescimento das formas dramáticas folclóricas da Índia, com ênfase na figura do herói-guerreiro, amplamente corroborada pelos épicos, pelos Puranas e toda sorte de histórias de heróis locais. Segundo De Bruin:

O culto e a identificação com os heróis através da representação dramática parecem muito antigos. Alguns estudiosos acreditam que ele seja pré-ariano e baseado nos cultos Dravidianos de adoração dos heróis. Neste caso, remetendo ao período Cankam, nos séculos I e II d.C. (De Bruin, 1999, p. 91)

Tradicionalmente, narra episódios do Mahabharata numa versão regionalizada do épico, que difere em alguns aspectos do texto original, acrescentando passagens, personagens e situações que remetem à história do estado e ao imaginário coletivo, com seus bravos heróis e guerreiros míticos, como por

2003, p. 31). (Tradução nossa)

${ }^{4}$ The worship of and identification with heroes through dramatic representation seems to be very old, and is found throughout India. Some scholars believe it to be pre-Aryan and to be based upon regional, Dravidian cults of hero worship. In that case it is often traced back to the Cankam period (first two centuries A.D.). (De Bruin, 1999, p. 91). (Tradução nossa) 
exemplo, Mahaveeran, presente até os dias de hoje no Theru-K-Koothu, numa encenação ritual que envolve transe e sacrifício animal 5 .

É uma forma teatral narrativa que nasce no ambiente rural, que se vale de diferentes recursos cênicos para dar conta dos seus objetivos, partindo de uma origem ritual, associada principalmente ao Festival de Draupadi Amman e à encenação do mito de Draupadi, divindade feminina cultuada principalmente nos vilarejos rurais de Tamil Nadu.

Figura 2 - Mahaveeran, arquétipo do herói-guerreiro de Tamil Nadu.

Foto: cedida por Parthiban V

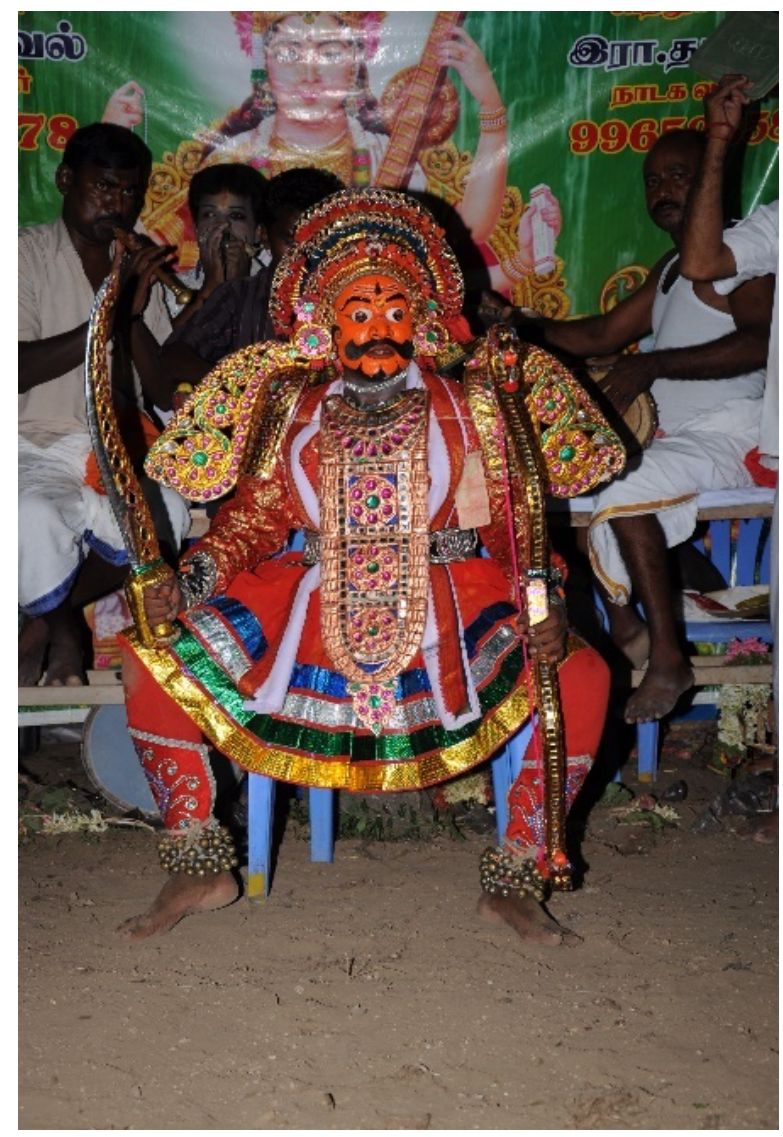

Sua função primordial é ritual, operando em dois níveis: espiritual (proteção e cura psíquica) e social (integração e repactuação do ethos coletivo). Sua função simbólica é preservar a castidade de sua divindade-mãe, Draupadi Amman ou

${ }^{5}$ Sobre isto, ver no youtube: https://www.youtube.com/watch?v=DOp6xhc2OLM 
Tirupataiyamman, contra o escárnio de seus algozes. Se ela se sentir respeitada e devidamente adorada, certamente a vida na vila, naquele ano, será muito produtiva e próspera. É para isso que todos/as trabalham e a razão pela qual o festival se repete ano após ano: para que as bênçãos da deusa recaiam sobre as vilas e seus/suas moradores(as), para que o princípio vital da energia criativa do feminino não cesse de fluir no âmago de sua vida espiritual e material, que no contexto da escrita deste artigo será entendido como processo de cura ritual coletiva, que reconecta os laços da ancestralidade à vida cotidiana e garante a saúde de sua coletividade de modo holístico. A esse processo, convencionou-se chamar de manutenção simbólica do Dharma, a conduta correta na vida, para que os laços morais, sociais e éticos que unem as comunidades sejam relembrados e repactuados, garantindo uma convivência harmônica para o próximo ciclo anual e transmitindo, para as novas gerações, os valores comunitários tradicionais. Desse modo, o conceito de Dharma aponta o caminho da cura coletiva e ritual por meio da ética (moralidade) expressa pela performance (estética).

Figura 3 - O martírio de Draupadi, encenado pela companhia Kattaikkuttu Sangam, de Kanchipuram. Foto: Edilson Castanheira

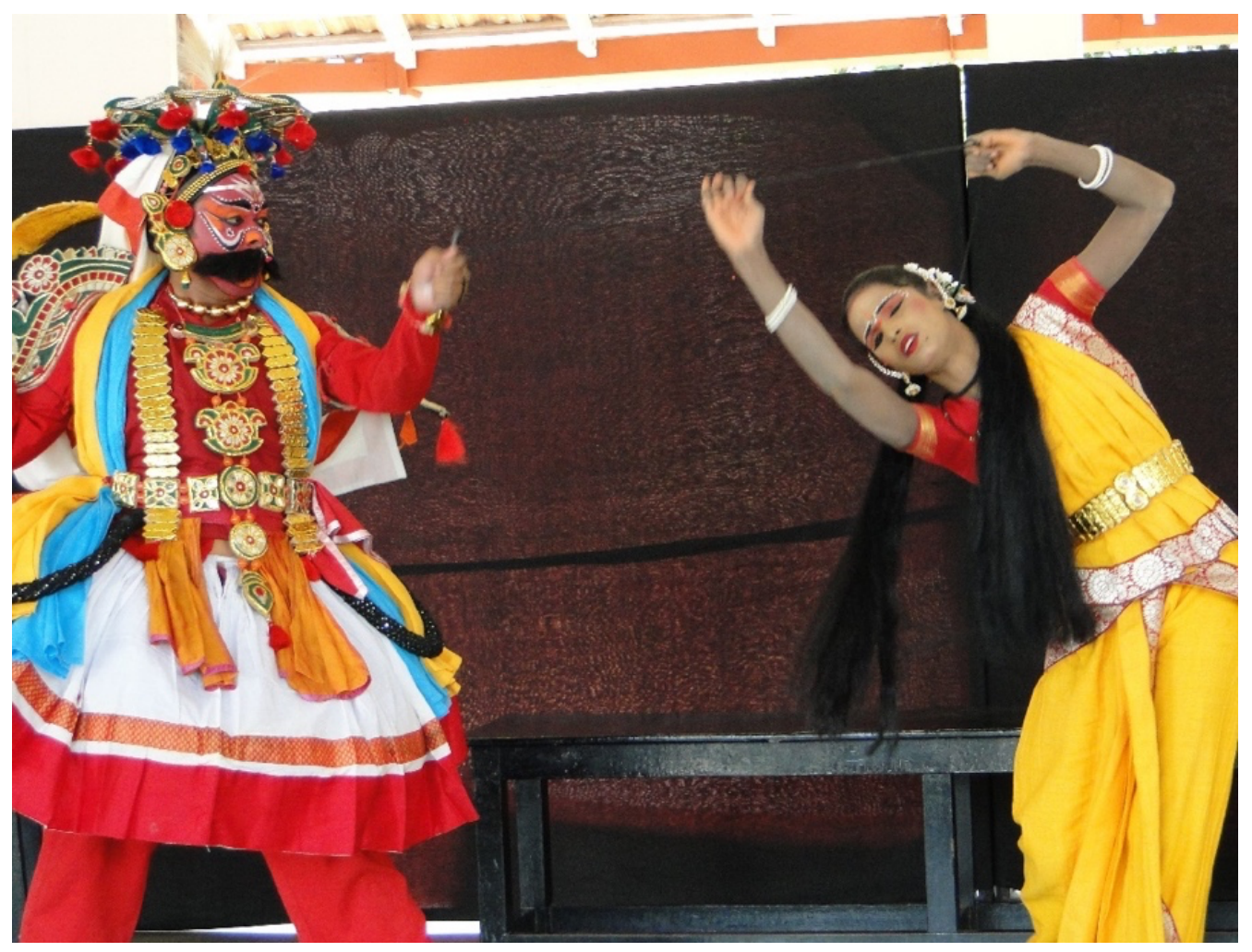


Dentre a imensa profusão de formas dramáticas populares que há na Índia e no próprio estado de Tamil Nadu, o Theru-K-Koothu possui a especificidade de ser um estilo bastante complexo em sua estrutura cênica e estética. Ele possui dois estilos principais ou Panis, com diferenças estilísticas que vão das mais sutis às mais acentuadas, conhecidos como Estilo do Norte ou Vatapanku (Distritos de Vellore, Tiruvannamalai, Cuddalore, Villupuram e Kanchipuram) e Estilo do Sul ou Tenpanku (Distrito de Thanjavur e no território independente de Pondicherry), formando diferentes linhagens que, eventualmente, intercambiam conhecimentos (mágicos e práticos), técnicas de atuação e artistas, entre si.

Longe de conceber a cultura folclórica como um subproduto da cultura clássica da Índia ou menos sofisticada que esta, as formas dramáticas folclóricas guardam considerável grau de sistematização e codificação cênicas que, diferentemente de sua irmã erudita, não possuem registro escrito, dependendo inteiramente da transmissão oral de saberes para se perpetuar, sedimentadas em diferentes clãs artísticos, comandados por um líder, o Vattyiar - ou como se diz na cultura clássica, o Guru.

Tradicionalmente, o Theru-K-Koothu é um ambiente teatral habitado por homens. Mulheres não são admitidas nas trupes e, como em muitas outras formas teatrais da Índia e do Oriente, há uma tradição refinada de homens especializados em representar papéis femininos, os Pen Veshams, comandados pelo Sutradhara - uma espécie de narrador, menestrel, diretor de cena em cena, e pelo Vidushaka - personagem cômico que faz contraponto ao Sutradhara, pontuando passagens dramáticas com comentários jocosos, grotescos e, não raro, mordazes e críticos. No Theru-K-Koothu, no entanto, estes dois personagens se fundem em apenas um: o Kattyakaram, que une o elemento épico e cômico em uma só figura e centraliza o comando da encenação, de forte caráter improvisacional.

Pode soar estranho, portanto, que sua origem esteja associada ao Festival de Draupadi Amman, uma divindade feminina ligada aos ritos agrários de fertilidade, colheita e plantio, próprios da cultura dravidiana, fundida simbolicamente na personagem Draupad, do épico Mahabharata. Devemos nos lembrar, no entanto, que as Ammans, ou grandes mães, são parte fundamental da cultura agrária de 
todo sul da Índia e que, embora a religião predominante no estado seja o Hinduísmo, nas vilas remotas, distantes dos centros urbanos, as divindades préarianas, em especial as femininas, prevalecem, porque seu culto remete às dinâmicas da vida cotidiana e não requerem a conformação de rituais complexos, que exigiriam a presença de um sacerdote para serem realizados. É o culto que atende às demandas da vida prática, o divino com quem se pode conversar e negociar sem intermediários, a possibilidade de transcendência e cura acessíveis aos "esfarrapados do mundo" (Freire, 1978, p. 17).

Dentro do contexto religioso e espiritual que é o Festival de Draupadi Amman, as apresentações de Theru-K-Koothu são o acontecimento central da festividade e comumente envolvem vários vilarejos e clãs familiares em sua organização e realização, idealmente anual, podendo durar até vinte e um dias, a depender das condições financeiras de seus/suas organizadores(as) e da própria pressão da comunidade. Acredita-se que, quando o festival não acontece, a colheita é mais fraca naquele ano, os animais não dão boas crias, assim como as mulheres e toda a vida nas vilas se torna mais árida e menos próspera. Portanto, reviver o mito de Draupadi é garantir a continuidade da própria vida material e simbólica destas comunidades. O festival compreende diferentes ações que vão dos (1) rituais religiosos, (2) contação de histórias e (3) encenações Theru-K-Koothu, divididas em dois tipos: (3.1) as encenações rituais que contam com a participação do público e (3.2) as encenações tradicionais de episódios do Mahabharata. 
Figura 4 - Arjuna Tapasu, encenação ritual que envolve atores e público durante o Festival de Draupadi Amman



Fonte: https://www.facebook.com/therukkoothu.therukkoothu

Durante sete noites até o penúltimo dia de festival, as trupes de Theru-KKoothu encenarão os episódios selecionados do Mahabharata, contando com a participação ativa da comunidade, que vai se transformando em diferentes personagens coletivos do épico ao longo dos dias. As apresentações acontecem em espaços variados da vila durante o dia, quando acontecem as encenações rituais com participação popular. À noite, começam as jornadas de Theru-KKoothu, que durarão toda a madrugada e apresentarão os episódios escolhidos pela comunidade, numa arena construída com esse propósito nas proximidades do templo. No penúltimo dia de festividade, a encenação tomará o centro da vila para reviver o tão esperado episódio de Duryodhana e Bhima, conhecido como Padukalam, com a destruição coletiva do totem gigante de Duryodhana e aparição de Draupadi para vingar sua humilhação, no limiar entre ficção e realidade. 
Acredita-se que, neste momento, os atores estejam em estado de transe ou Avesam. É exatamente esta intensa participação do público e o estado limiar de consciência criado que conferem ao Theru-K-Koothu seu caráter ritualístico mais proeminente. Os atores, neste momento, se tornam os próprios heróis míticos do Mahabharata ou as representações vivas dos ídolos estáticos dos templos. O público, que participa ativamente da encenação da batalha final, é remetido à condição simbólica de soldados/as do exército vitorioso e transportados/as, pela ficção, para a realidade do mito. Nesse espaço não mensurável ou palpável da experiência mítica comunal, a consciência atinge modos mais sutis de percepção da realidade individual e coletiva. No retorno à vida real, tais ensinamentos mágicos e secretos se harmonizarão à dinâmica da vida privada e pública, garantindo que os valores do Dharma e o princípio da energia vital criativa, tão caros à experiência humana compartilhada e apontados aqui como formas de cura coletivas, se manifestem plenamente.

Frasca (1990, P. XI), primeiro pesquisador estrangeiro a estudar o Theru-KKoothu, aponta para o caráter liminar e ritual do estilo, partindo dos conceitos desenvolvidos por Turner no livro From ritual to theatre (1982), e observando suas três fases: separação da realidade, estabelecimento de uma communitas ficcional e reagregação ao real. Pode-se concluir desse contato com o Theru-K-Koothu que toda experiência de cura e transformação que sua performance propicia advém do tensionamento de forças imaginárias e invisíveis a impulsionar o crescimento psíquico dos indivíduos e a saúde de suas coletividades, visando à manutenção de seus valores ancestrais e o bem comum na vida mundana, numa imbricação perfeita entre vida e arte.

\section{Um novo mundo desencantado}

Exponho agora o modo como me aproprio do conceito weberiano de "desencantamento do mundo", valendo-me da concepção de que há dois mundos opostos: o primeiro, animista, associado à magia, repleto de forças desconhecidas a dirigir o destino dos seres; um mundo sobrenatural, não dual, onde todas as 
forças operam em misteriosa harmonia, para além do entendimento humano. Este seria o mundo onde nasceu o Theru-K-Koothu.

O segundo, seria o mundo deflagrado pelo Iluminismo, no Ocidente, tomado por uma concepção de religião que pressupõe uma doutrina racional, com postulados éticos e morais a serem seguidos segundo a vontade de um deus que deve ser obedecido, estimulando práticas ascéticas que colocam o ser humano como responsável por sua salvação neste mundo. O mundo do sobrenatural dava lugar ao mundo dos grandes avanços das ciências e das tecnologias, transformando profundamente a mentalidade do sujeito do seu tempo, com consequências diretas sobre o mundo simbólico e espiritual que o precedia.

Certamente, não é possível utilizar o conceito weberiano de "desencantamento do mundo" (entzauberung der welt) para se compreender o complexo universo mítico-mágico-religioso hindu segundo sua definição original, dada a divergência de contextos em que operam, mas podemos buscar algumas aproximações que nos ajudem a sustentar o argumento deste artigo.

Podemos, por exemplo, criar um paralelo justo - apenas para nos ajudar a compreender como o conceito está sendo utilizado neste outro contexto - entre a concepção protestante de salvação pela ação ética, com a concepção hinduísta de Dharma, a definir a conduta correta do/a indivíduo/a no mundo, em busca da liberação ou Moksha. Ao nos permitirmos fazer esta ilação pontual, veremos o hinduísmo também como uma doutrina racionalista, dominada por uma classe de sacerdotes altamente intelectualizada e por práticas ascéticas rígidas e complexas que, ao seu modo e, neste caso, afastando-se de qualquer semelhança à liturgia protestante, acaba por também renegar certos aspectos anímicos da cultura préariana ${ }^{6}$ para fazer prevalecer os valores que sustentavam a visão de mundo indoariano.

\footnotetext{
${ }^{6}$ Cultura pré-ariana: refere-se uma das populações mais antigas do sul da Índia, vinculada ao povo dravidiano que também ocupava regiões do Paquistão, Afeganistão, Nepal, Maldivas, Bangladesh e Sri Lanka, por volta de 2.000 a.C. No sul da Índia, em especial no estado de Tamil Nadu, há traços muito preservados dessa cultura nas tradições religiosas, performativas e nos hábitos culturais locais, que conectam a grande tradição (Hinduísmo) à pequena tradição (práticas anímicas e xamânicas do período dravidiano).
} 
Trata-se, portanto, de um deslocamento de eixo de poder que adveio com o Iluminismo no Ocidente - e, antes mesmo disso, no Oriente, de um mundo mágico-mítico para um mundo metafísico-religioso, da vitória do sacerdote sobre o feiticeiro, com todas as consequências que esta transformação operou no mundo visível e invisível, nos/as indivíduos/as e suas coletividades. O Theru-KKoothu é uma reminiscência deste mundo encantado; revela aspectos desta cultura ancestral, mas também absorve práticas hinduístas tradicionais que, ao longo do tempo, deram-lhe formas e contornos específicos.

O "desencantamento do mundo" seria, nesta ótica, a fragilização do tecido social, cultural e espiritual que deu origem ao Theru-K-Koothu, colocando-o numa posição de vulnerabilidade no cenário pós-moderno, em que sua existência é, a todo momento, colocada em xeque; terreno limiar e perigoso, é, no entanto, potencialmente transformador. O desencanto seria o resultado natural da desmistificação das grandes narrativas espirituais e artísticas que lhes deram origem, deixando seus artistas e toda a rede de relações simbólicas, comunitárias e sociais que se estabeleciam, por meio deles, extremamente esvaziadas de sentido, descontextualizadas, desconfortavelmente fora do tempo ou da moda num país onde o cinema local é a grande paixão nacional, a definir não apenas novos comportamentos sociais, culturais, morais, mas também a estabelecer novas definições e funções para a arte, para além daquelas buriladas arduamente por milênios pela cultura clássica e folclórica da Índia.

Apesar de tudo quanto foi dito, o conceito de "desencantamento do mundo" não reflete a priori uma visão pessimista, desiludida ou de certo saudosismo de uma idade do ouro em que o ser humano fora, outrora, feliz; tampouco reflete a ideia de secularização, embora se relacione também aos avanços da ciência e da tecnologia que, além de não nos oferecer a redenção esperada, seja ela entendida como Moksha (liberação) ou cura (capacidade de imaginar um futuro partilhável possível), também não dão conta de responder à questão ontológica sobre o sentido último da existência ou seu completo esvaziamento em épocas de pouca empatia e alteridade.

Trata-se, sobretudo, de pensar um mundo desmistificado, fustigado pela 
racionalização crescente das religiões, das ciências e das tecnologias que, chegando aos seus extremos e idiossincrasias, nos levam de volta à necessidade existencial de retomada deste universo mágico-simbólico abandonado, dessa possibilidade de cura e transformação por outras vias de expressão e relação, garantindo, deste modo, uma existência mais satisfatória ou um novo caminho para o encantamento, por meio da ação coletiva e simbólica no mundo.

Partindo deste pressuposto, temos novamente as artes dramáticas a oferecer-nos um caminho e uma pista: seja por meio da revalorização das culturas dramáticas tradicionais, que nos oferecem vislumbres generosos deste outro mundo perdido; seja por meio do surgimento de novas práticas teatrais no cenário contemporâneo que, trabalhando neste contexto liminar, fragmentado e instável, procuram restabelecer contato com este mundo mágico marginalizado como proposta social-ética-política-mítica-espiritual da existência, sintetizando o melhor destes dois mundos em busca de produzir seu reencantamento, como projeto estético para o/a indivíduo/a do século XXI.

\section{O reencantamento do mundo}

Avançaremos agora para a problematização da abordagem que o conceito ganha na obra de Erika Fischer-Lichte, The transformative power of performance: a new Aesthetics (2008), apontando as estratégias de que se valem as artes da cena contemporâneas para produzir novos modos de encantamento mais afeitos às demandas do mundo pós-moderno, em relação direta ao conceito de liminaridade apresentado por Ileana Diéguez Caballero, no livro Cenários Liminares. Teatralidades, performances e políticas (2016).

Espera-se compreender de que modo a retomada de uma perspectiva ritual atualizada no tempo-espaço, no campo da performance teatral, em todas as modalidades que assume no pós-moderno (teatro, dança, dança-teatro, happenings, instalações, manifestações, rituais, paradas, desfiles etc.), corrobora e reafirma o projeto estético de novo encantamento do mundo, seja pela retomada de aspectos da cultura tradicional, depositária original deste saber mágico-mítico 
e propiciadora de uma certa qualidade de presença cênica condensada e intensificada pelo evento dramático-ritual, que tem interessado particularmente os/as artistas da cena contemporânea; seja pela produção de novas performatividades, hibridismos, teatralizações, que colocam na pauta de discussões os paradigmas institucionalizados da arte e da não-arte, promovendo uma reflexão sobre a sempre tênue e questionável fronteira entre arte e vida, que é um dos pilares para se compreender a ideia de reencantamento nos textos de Fischer-Lichte e Caballero.

Comecemos pela definição do conceito de liminaridade, segundo a ótica da teatralidade apresentada por Caballero - já um desdobramento do conceito de liminaridade apresentado por Victor Turner no campo da Antropologia Social:

\footnotetext{
Interessa-me estudar a condição liminar que reside numa parte dessas teatralidades atuais, nas quais se entrecruzam não só outras formas artísticas, mas também diferentes arquiteturas cênicas, concepções teatrais, olhares filosóficos, posicionamentos éticos e políticos, universos vitales, circunstâncias sociais (Caballero, 2016, p. 21).
}

O conceito de liminaridade associado a esta concepção de teatralidade que transforma os/as sujeitos/as, os/as corpos/as, o espaço-tempo, criando situações de ficção dentro da realidade do fato, são apresentadas neste artigo como condição sine qua non para o estabelecimento de práticas que, associado à "condição ética a criação estética" (Caballero, 2016, p. 21), podem conduzir a vislumbres de reencantamento do mundo ou cura coletiva sistêmica, aos moldes do que se vê na tradição do Theru-K-Koothu.

Dialogando com o sintagma weberiano, Fisher-Litche argumenta que, historicamente, a experiência estética sempre foi um dos portais mágicos a viabilizar o reencantamento do mundo, por seu potencial transformador dos/as indivíduos/as e suas coletividades, suscitando outras qualidades de presença e de relação com/no mundo que, revolvendo o adormecido e em vias de perder-se na inércia ou no esquecimento, trazem à tona uma nova pulsão de vida aos/as corpos/as e mentes, por meio de práticas e ações que, longe de qualquer idealização, tendem à desestabilização, ao incômodo, ao desajuste. 
Esta experiência é vista pela autora, em si mesma, como o próprio reencantamento, para não aludir à ideia sentimentalista de volta a um passado mágico glorioso. A experiência estética, que é um processo de percepção/recepção, é também, em essência, uma experiência liminar, compreendendo-se que a liminaridade é condição essencial para efetivar processos profundos de transformação, podendo ser traduzida por situação limítrofe, de crise, "contagiosa como a peste" (Artaud, 2012, p. 27), a promover transformações nas esferas pessoal e social que, por suas qualidades intrínsecas, podem levar ao abalo das estruturas, à negação das verdades, à transgressão das regras e do status quo, em síntese, levar a profundos processos de cura e transformação.

Essa experiência estética já nos foi exaustivamente apresentada por meio do conceito aristotélico de catarse, esteio do pensamento teatral no Ocidente, mas também aparece na cultura hindu pela Teoria Estética de Rasa, a conduzir os/as indivíduos/as rumo à experiência com o sagrado, não pelo terror e a piedade, mas por meio dos sentimentos e estados emocionais elaborados conscientemente para produzir tal e qual efeito sob o espírito humano. Por caminhos diferentes, ambas se materializam na presença compartilhada de atores/trizes e espectadores(ras); são, também, limitadas ao tempo-espaço do evento e promovem, há milhares de anos, vislumbres de reencantamento por meio de diferentes estratégias cênicas ou performativas, se preferirmos. No entanto, no cenário pós-moderno, outras possibilidades de experiência estética se apresentam, assim como outros tipos de performance que acrescentam relativa complexidade ao fenômeno, embaralhando arte e vida, levando a ideia de reencantamento para muito além do espaço organizado da cena, acertando em cheio a esfera da vida cotidiana, o mundo real, temporal e efêmero, necessitando, portanto, de novas estratégias detonadoras e reveladoras desta experiência.

Dentro deste contexto, as “staging techniques" (Fischer-Lichte, 2008, p. 197), emergindo como desdobramento do conceito teatral tradicional de mise-enscène, refletem uma tendência do contemporâneo à estetização e à teatralização da vida, valendo-se de técnicas cênicas específicas para promover ações que 
extrapolam o campo artístico - como, por exemplo, eventos esportivos, políticos, festivais, paradas, "ações cidadãs" (Caballero, 2016, p. 21), entre outros. Este deslocamento nos remete às discussões atuais sobre as fronteiras, cada dia mais difíceis de precisar, entre arte e não-arte e sobre o próprio imbricamento arte e vida, estabelecendo uma lógica dialética na qual prevalece não a ideia de "uma coisa ou outra", mas de "uma coisa e outra" (Fischer-Lichte, 2008, p. 204) - o que elimina todo tipo de pensamento excludente baseado nesta dualidade, aproximando, inclusive, Ocidente e Oriente em suas diferenças complementares.

Por esta outra perspectiva, por meio das staging techniques, entendidas como estratégias performativas ou ferramentas abertas, seria possível criar outros tipos de materialidades, de fisicalidades através da presença compartilhada entre seus/suas fazedores(ras) (atores/trizes e público), além de outros modos de relação e de recepção menos previsíveis e controláveis que, quebrando a lógica do institucionalizado ou propondo a relativização dos cânones definidos pelo institucional, levam a um novo olhar para o mundo interior e exterior, que é uma possibilidade de reencantamento não romantizada e potencialmente transformadora dos/as indivíduos/as nos dias atuais - ainda que dure tão somente o instante do acontecimento mobilizador.

Reencantar-se é curar-se. Reencantar o mundo é colocar um bálsamo sobre suas feridas - mas sem apagá-las, porque apagamento é ausência de história e, sem história, não há pertencimento nem superação. É abrir frestas de entendimento e possibilidade onde antes morava desencanto e pathos. As artes performativas têm, portanto, muito a oferecer nesse novo cenário global póspandêmico, assim como o Theru-K-Koothu tem feito por suas coletividades há centenas de anos, ainda que consideremos os desafios tremendos que eles mesmos enfrentam para sobreviver no século XXI.

\section{As cidades desencantadas e as frestas de reencantamento}

Não é simplesmente a falta de interesse artístico que mantém as classes abastadas de Chennai longe dos festivais folclóricos. Pode haver receio 
de que a experiência do festival do Mahabharata venha a perturbar o delicado equilíbrio da sociedade civil (Hollander, 2007, p. 80)7.

Imerso numa tradição cultural engajada em conectar o material e o espiritual há milênios, o Theru-K-Koothu também sofre com uma certa corrosão e enfraquecimento desta estrutura original, a requerer de seus artistas novas staging techniques que garantam sua sobrevivência num novo cenário local, mas globalizado, paulatinamente afetado pelo Ocidente e suas estéticas, e pela própria precarização de sua condição social e econômica. Uma das estratégias mais notáveis tem sido a ida destes artistas para os grandes centros urbanos do estado, em especial a capital, em busca de garantir sua sobrevivência material e simbólica.

O choque entre estes dois sistemas de valores tão distintos é evidente, mas longe de corroborar uma visão pessimista; como situação de crise, limítrofe, ela é propulsora de novas soluções e possibilidades que, se em alguns aspectos implicam numa certa desritualização do estilo, por outro lado abrem novas perspectivas de difusão a uma população jovem, essencialmente urbana, que pouco conhece da tradição e que pode vivenciá-la por uma nova ótica, não necessariamente inferior à original, mas sensivelmente diferente.

Essa diferença merece ser observada com atenção e cuidado, especialmente quando o Theru-K-Koothu começa a ser visto e vendido como produto exótico para entreter plateias endinheiradas, que veem nele a cara da cultura tradicional de Tamil Nadu, uma reminiscência de um passado mítico idílico, ou visto com saudosismo e sentimentalismo por uma geração que, não tendo nascido nesse ambiente, ainda se lembra dele na figura de seus antepassados mais próximos. Uma saudade de algo que parece importante por alguma razão que já não sabemos bem qual é. Intuo que seja o chamado de seus ancestrais, na forma de traços preservados da vida das aldeias nos grandes centros urbanos, que transparecem nos pequenos e comezinhos atos cotidianos, muitas vezes executados de forma ritualmente desapercebida, mas não totalmente

7 It's not simply a lack of artistic interest that keeps the upper classes of Chennai away from their folk festivals. There may well be a fear that the experience of Mahabharata festival will upset the delicate balance of civil society. (Hollander, 2007, p. 80). (Tradução nossa) 
inconsciente.

Entretanto, há também bons exemplos desse processo de aproximação entre rural e urbano, tradicional e contemporâneo, representado por toda uma rede de apreciadores(ras), conhecedores(ras), mecenas, pesquisadores(ras) e artistas a estimular a vinda destes artistas tradicionais para as cidades, de forma a permitir que as novas gerações não se percam da cultura e dos valores tradicionais. Que o potencial transformador e de cura coletiva que estas novas gerações carregam possam se manifestar mesmo em contextos adversos, como o que se vê nos caóticos centros urbanos da Índia. De Bruin enxerga esse cenário, aparentemente conturbado, de modo bastante oportuno:

"Kattaikkutu não é capaz de sobreviver à competição com o popular cinema Tamil", "a tradição certamente deve estar morta ou morrendo" e, "de qualquer maneira, é uma forma de teatro desatualizada, adequada apenas para públicos iletrados e deslocada em um ambiente moderno e em uma sociedade em rápida mutação". Estas são algumas das opiniões expressas por pessoas urbanas de classe alta e média, que parecem completamente fora de contato com o ambiente rural onde estas formas de arte ocorrem. Na realidade, o teatro está muito vivo e, a julgar pelo crescente número de apresentações oferecidas por grupos profissionais, ganhando popularidade ${ }^{8}$ (De Bruin, 1999, p. 19).

Observando todo esse cenário, fui levada, num primeiro impulso, a pensar em todas essas transformações como uma perda, atropelando e desfigurando a tradição. Entretanto, não seria isso uma visão simplista ou romantizada da questão? Uma certa nostalgia de uma beleza pura, original, que não pode ser maculada na cultura dos outros? Reminiscências de uma postura orientalista imperdoável, neste caso! Não seria possível conceber, por outro lado, que todas essas transformações estariam cumprindo a função de criar uma ponte necessária - entre o tradicional e o contemporâneo, acessível e inteligível para as novas gerações, garantindo a preservação de suas tradições e valores mais íntimos

\footnotetext{
${ }^{8}$ Kattaikkutu has not been able to survive the competition with the popular Tamil film, "the tradition certainly must be dead or dying" and "anyway it's an outdated theatre form, fit only for uneducated village-audiences and out of place in a rapidly changing, modern society". These are a few of the opinions vented by urban upper and middle-class people, who seem completely out of touch with the rural folk performing art forms. In reality, theatre is very much alive and, judging from the increasing number of performances offered to professional groups, gaining in popularity. (De Bruin, 1999, P. 19). (Tradução nossa)
} 
e preciosos? Não seria essa uma estratégia de aproximação e sobrevivência simbólica válida que não exclui, em si, vislumbres de encantamento, beleza e respeito às tradições? Vejamos o que nos diz Caballero,

Insisto nesta dimensão da liminaridade, fora da esfera estritamente sagrada, pelo potencial que representa para refletir as situações cênicas e políticas inseridas na vida social, propiciadoras de trânsitos efêmeros, mas de alguma maneira também transcendentes. [...]. O retorno ao "real" faz um apelo ao entrecruzamento entre o social e o artístico, acentuando a implicação ética do artista (Caballero, 2016, p. 38-44).

No entanto, as perguntas incômodas persistem: mas os artistas de Theru-KKoothu têm consciência dessa realidade ou simplesmente respondem a ela? Eles têm possibilidade real de escolha? A cidade acolhe ou engole esses artistas e sua tradição? Resta-nos saber em que medida os artistas de Theru-K-Koothu estão instrumentalizados a negociar com esta outra realidade e suas demandas, para garantir sua sobrevivência e a sobrevivência de sua forma de arte, seu ethos.

Se o conceito de reencantamento remete, essencialmente, à transformação dos/as sujeitos/as e coletividades como forma de cura, não seria justo considerar que existem transformações mais ou menos dignas - mas sim assumir que, qualquer transformação, por menor que pareça, pode ser precursora de insights e condições de empoderamento que respondem às necessidades urbanas, tão diversas das necessidades próprias do ambiente rural. Seguindo a ótica apresentada por Fischer-Lichte de "uma coisa e outra", creio que podemos dizer que há validade nessa equação. A cidade oferece acolhimento, permite relações mais verticais e descoladas das obrigações entre clãs, linhagens e famílias do ambiente rural, mas exige contrapartidas que precisam ser, a todo tempo, negociadas em processos nem sempre igualitários - mas sempre abertos, imprevisíveis, potencialmente transformadores por esta mesma condição. Não há como eliminar o risco inerente a esta migração. Os processos contínuos de apropriação cultural pressupõem engolir e deglutir, o tempo todo, a desorganização de certa lógica comunitária e sua reorganização no espaço das cidades - a tal liminaridade de que vimos falando até aqui, com todo risco e potência implícitos. Os dados ainda estão sendo lançados, não nos esqueçamos. 
Se vencer, o Theru-K-Koothu assume o reino de Indraprastha. Se perder, parte para o exílio com os Pandavas, seus ancestrais guerreiros do Mahabharata.

\section{Considerações finais}

Ninguém se liberta sozinho, os homens se libertam em comunhão.

(Freire, 1978, p. 27)

Mas, então, o que seria e como se daria um processo de cura por meio de eventos cênicos no cenário pandêmico e pós-pandêmico?

Se entendermos o conceito de cura como restaurar a fonte da energia vital criativa, o ethos coletivo, reencantar a si a ao mundo para transmutar, ressignificar os velhos padrões de pensamento e comportamento, restabelecer o espaço liminar do simbólico na vida cotidiana através de novas estratégias cênicas, então, perceberemos que se trata de um processo claramente pedagógico. Na perspectiva apresentada, o processo de cura se dá em duas esferas complementares: individual e coletiva, emancipando sujeitos/as e coletividades, simultaneamente.

Na esteira desse pensamento freiriano, podemos dizer que nos encontramos em uma "situação-limite", que nos apresenta um problema e exige de nós um “ato-limite" (Freire, 1978, p. 106), de modo a produzir o "inédito viável” (Freire, 1978, p. 110), capaz de transformar a enrijecida realidade em uma realidade maleável, que aceite o trato de nossas mãos a moldá-la. Se a situação-limite ou liminar, para nos mantermos atados às concepções de Caballero, é representada pelo pathos, o ato-limite é, portanto, o ethos, como o evento cênico, ação performativa, que materializa a possibilidade da cura, colaborando no processo de restauração do indivíduo e de sua sociedade (Dharma), por meio de novas staging techniques, outras performatividades engajadas no processo de produzir o "Ser Mais" no mundo e para o mundo (Freire, 1978, p. 30).

Há, portanto, que se compreender estas outras performatividades ainda por 
serem experimentadas como (1) projeto pedagógico, porque exigem de nós a coragem de ir além das epistemes hegemônicas nas salas de aula e de ensaio, ofertando escuta sensível às vozes silenciadas e historicamente apagadas; (2) projeto ecológico, porque está intrinsicamente ligada à preservação do planeta como condição sine qua non de nossa existência material e simbólica e (3) projeto estético-ético, porque exige de nós a coragem de reinventar e bradar aos quatro ventos um projeto de mundo no qual não seja embaraçoso falar de humanidade e dos valores que nos tornam humanos, com todas as implicações políticas e sociais que atravessam essas três esferas.

Estas novas performatividades ou eventos cênicos devem ser, portanto, um vislumbre desse ousado projeto dentro das universidades, nas salas de ensaio e espetáculo, nas ruas e em qualquer lugar em que se ouse pronunciar a "palavrageradora" (Freire, 1978, p. 92), o gesto-gerador; aquele que carrega outras palavras e gestos, as ideias que eles enunciam, os conceitos que engendram, as ações que evocam e as grandes transformações que alavancam.

Se o cenário atual nos impõe restrições e nos faz caminhar em um terreno desconhecido e limitante para os padrões da experiência teatral compartilhada entre artistas e público, ele também abre um espaço generoso de vazio. E o vazio sempre foi um espaço fértil para a criação artística. Um vazio dolorido e incômodo, é verdade, porque não solicitado; fomos tomados/as de assalto por ele e dançamos, constrangidos/as, ao sabor de suas melodias. Nem por isso ele deixa de ser um espaço de potência a ser imaginado e reinventado.

Isso me faz lembrar do penúltimo dia do Festival de Draupadi Amman quando, após a destruição catártica do totem de Duryodhana, veio de longe, cantando, dançando libidinosamente e dizendo impropérios, a própria Morte como alegoria final da jornada épica, experimentada, na carne, pelos(as) moradores(as) dos vilarejos, durante vinte e um escaldantes dias de festival no alto verão do sul da Índia. Os/as participantes dançavam com ela, riam de suas grosserias lascivas, celebravam a vida simples em êxtase e regozijo, porque sabiam que ela é efêmera e de viés! O circuito se completava nesse imbricamento entre arte e vida, processo profundo de separação, communitas e reagregação. Os/as agricultores/as podiam, 
agora, voltar para suas extenuantes atribuições agrícolas, pois seu futuro simbólico estava salvaguardado. A performance ritual reestabeleceu o Dharma, os pactos sociais e a saúde psíquica dos/as indivíduos/as por mais um ciclo de vida. A cura não havia sido algo que surgiu espontaneamente, mas algo colocado ali pelo evento cênico organizado e pela presença física compartilhada e comprometida de seus/suas fazedores(as).

No momento, porém em que se comece a autêntica luta para criar a situação que nascerá a superação da velha, já se está lutando pelo Ser Mais. E, se a situação opressora gera uma totalidade desumanizada e desumanizante, que atinge aos que oprimem e aos oprimidos, não vai caber, como já afirmamos, aos primeiros que se encontram desumanizados pelo só motivo de oprimir, mas aos segundos, gerar de seu ser menos a busca do Ser Mais de todos (Freire, 1978, p. 35).

\section{Referências}

ARTAUD, Antonin. O teatro e seu duplo. São Paulo: Martins Fontes, 2012.

CABALLERO, Ileana Diéguez. Cenários Liminares. Teatralidades, performances e políticas. México: EDUFU, 2016.

DE BRUIN, Hanne M. Kattaikkuttu. the flexibility of a South Indian theatre tradition. Netherlands: Egbert Forsten, 1999.

FRASCA, Richard A. The Theatre of Mahabharata: Terukkuttu Performances in South India. Honolulu: University of Hawaii Press, 1990.

FREIRE, Paulo. Pedagogia do Oprimido. 6a ed. Rio de Janeiro: Paz e Terra, 1978.

FISCHER-LICHTE, Erika. The transformative power of performance: a new aesthetics. Tradução: L. Saskya Jan. Londres: Routledge, 2008.

HILTEBEITEL, Alf. The Cult of Draupadi. Vol. 1 Mythologies: From Gingee to Kuruksetra. Chicago e Londres: The University of Chicago Press, 1988.

HILTEBEITEL, Alf. The Cult of Draupadi. Vol. 2 On Hindu Ritual and the Goddess. Chicago e Londres: The University of Chicago Press, 1988.

HOLLANDER, Julia. Indian Folk theatres. Theatres of the World. London e New York: Routledge Group, 2007. 
PIERUCCI, Antonio Flávio. O desencantamento do mundo. Todos os passos do conceito em Max Weber. São Paulo: Editora 34, 2003.

TURNER, Victor. From ritual to theatre: the human seriousness of play. New York: Performing Arts Journal Publications, 1982.

WEBER, Max. Sociologia das Religiões. Coleção Fundamentos da Filosofia. São Paulo: Ícone Editora, 2015.

Revisora - Profa. Dra. Carla Moreira Kinzo

Recebido em: 25/08/2020

Aprovado em: 19/04/2021 